\title{
Mental Capacity and the Applied Phenomenology of Judgement
}

\author{
Wayne Martin* \\ Essex Autonomy Project \\ wmartin@essex.ac.uk \\ Ryan Hickerson \\ Western Oregon University \\ hickersr@wou.edu
}

\begin{abstract}
We undertake to bring a phenomenological perspective to bear on a challenge of contemporary law and clinical practice. In a wide variety of contexts, legal and medical professionals are called upon to assess the competence or capacity of an individual to exercise her own judgement in making a decision for herself. We focus on decisions regarding consent to or refusal of medical treatment, and contrast a widely recognized clinical instrument, the MacCAT-T, with a more phenomenologically informed approach. While the MacCAT-T focuses attention on individual cognitive performance criteria, an approach oriented by second-person phenomenology brings into view the complex role of time, others and identity in constituting the capacity for individual autonomous judgement. Our phenomenological analysis has consequences both for the practice of capacity assessments and for further research in this arena. Good practice in capacity assessment must attend to decision communities, distributed capacity, and temporal competence, while research on mental capacity will miss the phenomenon if it trains its focus 'between the ears.' We illustrate our approach by considering two recent cases of contested capacity: one involving cognitive disability in a dysfunctional decision community, the second presenting the possibility of competent decision-making under conditions of paranoid schizophrenia.
\end{abstract}

Our aim in what follows is to explore some aspects of the phenomenology of judgement. We begin with a few words about the way we propose to use these two terms. There is one way of understanding the term 'judgement' that confines its meaning rather sharply. Particularly in the history of logic, a judgement has sometimes been defined as a truth-evaluable content. To adapt Frege's formula, a judgement is that about which the question 'Is it true?' is appropriate. ${ }^{1}$ We recognize this narrow usage, which has the unmistakable advantage of being well-circumscribed; but we shall not follow it here. Our concern shall in the first instance be with the act of judgement, rather than with the

\footnotetext{
* Corresponding Author: Prof. Wayne Martin, Essex Autonomy Project, Department of Philosophy, University of Essex, Wivenhoe Park, Essex, CO4 3SQ, UK. This MS is an advanced draft of a paper currently under submission. (C) Wayne Martin and Ryan Hickerson, 2011.

${ }^{1}$ Frege 1918/1997: 327-28.
} 
truth-evaluable content that traditionally concerned logicians. We are also interested in a rather broader range of phenomena than the narrow definition allows. A scientific (or more broadly theoretical) judgement characteristically operates with respect to a truth-evaluable content. But we also speak of the exercise of judgement in other contexts. A manager or military commander exercises judgement in deciding how to deploy personnel; a citizen exercises judgement in deciding how to vote; we use judgement in deciding whether to sign a contract or a consent form or in preparing a will. And in the exercise of aesthetic judgement we may simply take pleasure in our experience of an art object. Instead of a formal definition we begin with a frankly circular indication of the phenomenon with which we shall be concerned: judgement is what judges do when they exercise their capacity to judge. ${ }^{2}$

The term 'phenomenology' also presents a range of familiar problems. Historically, the term has sometimes been used as the name for a distinctive method of inquiry. Exactly what that method should be has been the topic of rather bitter dispute. ${ }^{3}$ Once again, however, we shall depart from one established pattern of usage. 'Phenomenology,' as we shall use the term, is defined not by its method but by its theoretical aims, and by the range of objects with which it is concerned. Think of the analogy here with 'biology' or 'meteorology.' These are names of familiar and established sciences, where the range of the science in question is defined by the range of entities (or more broadly: phenomena) with which it is concerned. By definition, biology is concerned with living things; but the term itself tells us nothing about the proper method of investigating those things. Indeed part of the challenge of biology is to figure out what method or methods are best suited to the study of biological phenomena. We follow the same pattern with respect to phenomenology. The phenomenology of judgement is concerned with the exercise of judgement as an experience, as something that figures in the lived experience of those who exercise their capacity to judge. We take no general stand on the methods suited to study those experiences, and our methods here shall be ecumenical. ${ }^{4}$ We hope to illustrate ways in which traditionally first-personal, reflective phenomenological methods can usefully be supplemented by what we shall call "second-person phenomenology" - investigation which seeks to understand and articulate the experiences of others, particularly in the context of dialogic exchanges and clinical encounters.

Our conception of phenomenology is also distinctive for its intended practical import; indeed we think of our project here as a venture in applied phenomenology. Although phenomenology has sometimes gained a reputation as a wholly abstract, even abstruse theoretical endeavor, it has nonetheless often been put to practical use. A close study of our experience of things - of the ways in

\footnotetext{
${ }^{2}$ We hope that it is clear from the foregoing that the kinds of judges we have in mind need not wear robes and sit in wood-paneled courtrooms. Judges are simply those who exercise judgement; they include managers and military commanders and will-writers and citizens ... .

${ }^{3}$ For the canonical positions in the debate over phenomenological method, see Husserl 1913/1931 and the respective Introductions to Heidegger 1927/1963 and Merleau-Ponty 1945/1962. For recent naturalistic approaches to phenomenology see Dennett 1991 and Petitot et.al. 1999. On the contrast between 'straight' and 'hetero-' phenomenology, see Cerbone 2003.

${ }^{4}$ In various phases of its historical development there have been rather intense disputes about the demarcation of phenomenology from various other sciences - notably in the contexts of the disputes over psychologism. We have written about this history elsewhere (see Martin 1999 and 2005, Hickerson 2007) but it is not our intention to be drawn into these sorts of border disputes here.
} 
which things appear as what they are - may be put to practical use in producing a trompe l'oeil painting, in designing a cockpit, or in refining a remote digital workspace environment. For our part, we are interested in a range of applications that pertain to what is commonly known as 'capacity assessments' - the assessment, in particular, of the competence of persons to exercise judgement in making decisions for themselves. ${ }^{5}$

Capacity assessments have in recent years become an increasingly routine aspect of frontline professional activity: in legal proceedings, clinical medical contexts, police interventions, etc. Modern legal and administrative regimes are increasingly organised around a mandate to foster and protect human rights. Human rights legislation such as the European Convention on Human Rights or the UK Mental Capacity Act characteristically seek to guarantee significant forms of self-determination to adults, as for instance in the arena of medical law. In the UK, an adult has an absolute right to refuse medical treatment, even where doing so will lead to harm or death. But the enjoyment of such rights is characteristically conditional; it depends, in particular, on the individual's being possessed of the competence required to exercise them. ${ }^{6}$ Where capacity is found to be lacking, the patient's right of self-determination is characteristically replaced by a variety of paternalistic duties of care, by deference to advance directives, or by one or another form of surrogate decision-making. Hence the assessment of capacity - in particular the capacity to exercise one's own judgement in determining one's own affairs - has become a critical determinant of legal standing. Our hope is to bring a phenomenological perspective to this juridico-medical practice.

Before turning to the matter at hand, one final preliminary is in order, in this case pertaining to the generality - or lack thereof - in our results. Some have claimed for phenomenology results of quite strict universality and necessity. If phenomenology is indeed an eidetic science, then one might expect that a suitably perspicuous presentation of a single exemplary instance could adequately illuminate the whole class of phenomena to which it belongs. Our aims here are considerably more modest. We resist the temptation to make general claims about the phenomenology of judgement and decision. We suspect that the range of phenomena is too broad to admit of any straightforward generalization. For present purposes we propose to focus attention on some particular cases and features of the experience of judgement, in the hope of enriching some of the existing models and methods for assessing mental capacity.

Consider one such existing model, the so-called MacCAT-T: the MacArthur Competence Assessment Tool for Treatment. ${ }^{7}$ The MacCAT-T is a standardized tool designed for use in

\footnotetext{
${ }^{5}$ Except where otherwise indicated, we follow Appelbaum 2007 in using the terms 'competence' and 'capacity' interchangeably. (See in particular Appelbaum 2007: 1834.) The two terms have sometimes been used with different senses, but more often they occupy the same semantic position in different dialects of legalese. Where US courts speak of 'mental competence,' UK law typically invokes 'mental capacity.' For one formulation of a distinction between the two terms in a US context, see Marson 2002: 268-9.

${ }^{6}$ There is certainly an air of paradox in the thought that there might be conditions on a right that is itself described as absolute. Legally, the paradox is resolved by distinguishing between possessing the right and exercising it. Only a competent individual possesses the right to refuse treatment. In this sense possession of the right is conditional on competence. But for the competent individual, that right trumps all other considerations. It does not have to be weighed, for example, against the rights of others or the interests of the state. In this sense the exercise of the right is absolute.

${ }^{7}$ Grisso and Appelbaum 1998a and 1998b.
} 
assessments of the competence of medical patients to make decisions about their own medical care. ${ }^{8}$ The tool was developed with support from the MacArthur Foundation in the 1990s by Thomas Grisso and Paul Appelbaum, in large part on the basis of a historical study of case law. By surveying and distilling the methods used by courts in deciding cases of contested competence, Grisso and Appelbaum developed a simple and efficient standard instrument for use in conducting assessments of a patient's mental capacity in contexts requiring treatment decisions, e.g., whether to accept or refuse a recommended medical procedure, whether to be admitted to a psychiatric facility, etc. Compared to its predecessors, the MacCAT-T is distinctive in two respects. First, the test does not make use of a standard 'decision vignette' that all subjects are asked to review and discuss. Instead, the MacCAT-T relies on a semi-structured interview which is tailored in each instance to the particular circumstances and treatment decision faced by the patient at the time of the assessment. Secondly, the MacCAT-T is simple and efficient. Previous assessment methods required a 60-90 minute interview with a psychiatrist, and involved an intricate method of scoring responses, but the MacCAT-T can be administered in 15-20 minutes, and involves a relatively simple method of scoring. As a result it has become "the most widely used psychometric instrument in the assessment of capacity for treatment decisions,"9 and has been described as "a gold standard in clinical psychiatry." 10

Using the MacCAT-T involves examining patients in four separate areas of capacity: the capacity to understand treatment-related information; the ability to appreciate the significance of the information for their situation; the capacity to reason in the process of deciding upon a treatment and to compare alternatives in light of their consequences; and the ability to express a choice. ${ }^{11}$ In practice, much of the implementation of the test involves a method of "disclose and paraphrase." That is, the clinician "discloses" information regarding the patient's diagnosed condition and then asks the patient to explain in his own words what has just been disclosed. This exchange proceeds through several cycles: in the first instance pertaining to the medical diagnosis, then in turn regarding treatment options, risks and benefits, and so on. At the end of the interview the patient is asked to express a preference as to a particular treatment option. The instrument has been subjected to many trials, exhibits high 'interrater reliability,' and shows strong correlation between MacCAT-T scores and particular items on the Brief Psychiatric Rating Scale (BPRS). ${ }^{12}$

Before going further, it is important to be clear about what the MacCAT-T does not do. Grisso and Appelbaum have themselves repeatedly emphasised that a MacCAT-T assessment was never intended of itself to yield an overall determination of competence. By design, there is no such thing as a 'cut-off' score, so strictly it makes no sense to speak of 'passing' or 'failing' the MacCAT-T. To reinforce this point, Grisso and Appelbaum themselves distinguish between the measure of capacities on the one hand, and the assessment of competence on the other. The four constituent

\footnotetext{
8 "The MacCAT-T offers physicians and other health professionals practical guidance in their assessments of patients' decision-making capacities in the context of informed consent to treatment." Grisso and Appelbaum 1998b: 1.

${ }^{9}$ Appelbaum 2007: 1837.

${ }^{10}$ Breden and Vollmann 2004: 274.

${ }^{11}$ Grisso and Appelbaum 1998b: 1-2.

${ }^{12}$ Grisso et al. 1997, Cairns et al. 2005, Dunn et al. 2006.
} 
capacities (understanding, appreciation, reasoning, expressing a choice) are each scored, yielding a single numerical value for each. But strictly speaking it is a misuse of the tool to add these four values together into a single score. An assessment of overall competence requires that the results are interpreted by a clinician, taking in to account "other clinical and background data, as well as ... the context in which the interview procedure was employed."13 But Grisso and Appelbaum have also acknowledged that these warnings are often overlooked. ${ }^{14}$ Indeed it has become common in research studies deploying the MacCAT-T to use a threshold of 2.5 standard deviations below the population mean as a surrogate construction for incompetence. ${ }^{15}$

It should be clear from the foregoing that the MacCAT-T places quite a high value on what we might call individual cognitive performance criteria in assessing competence to make treatment decisions. That is, the assessor prompts the patient to engage in a certain range of behavioural performances that themselves demonstrate individual cognitive skills: the ability to follow a moderately complex medical description, to retain the information that has been provided, and to reproduce the information in different words. To be sure, the assessment of such performances can only yield an overall competence assessment once it has been combined with ancillary information, particularly about the degree of risk and benefit at stake in the specific treatment decision at issue. ${ }^{16}$ But the core of the MacCAT-T lies in its quantitative psychological assessment of individual cognitive performance.

This feature of the tool has itself provided the basis for a more recent body of 'neuropsychiatric' research that developed in the decade following the introduction of the MacCAT-T. The aim in this research has been to identify the physiological basis of competence by identifying specific neurocognitive deficits strongly correlated with incapacity. In pursuit of this goal, MacCAT-T scores are used as dependent variables in experiments seeking correlations with performance on a variety of neurocognitive and neurophysiological tests. The ultimate aim is to establish a "conceptual and empirical bridge between bioethical, legal, and neuropsychological approaches to understanding meaningful decision-making processes." 17 To date the results from this research paradigm have been meagre. A 2007 meta-analysis surveyed sixteen studies and reached a largely negative conclusion: "No particular cognitive abilities or tests stood out as consistently unique predictors of overall decisional capacity, and there were no clear patterns of differential relationships between specific neuropsychological abilities and specific components of decisional capacity." ${ }^{18}$ But what matters for

\footnotetext{
${ }^{13}$ Grisso and Appelbaum 1998b: 2. Chapter 7 of Grisso and Appelbaum 1998a proposes a procedure for using MacCAT-T results in a balancing exercise intended to yield an overall capacity judgement for particular cases. ${ }^{14}$ Grisso and Appelbaum 1996: 168. The phenomenon of "instrument creep" itself merits scrutiny, and is an area in which we believe that resources from the phenomenological tradition might be usefully applied to juridicomedical practice. We reserve discussion for another occasion.

${ }^{15}$ See for example Moye et al. 2006, 80: "To determine the percentage of participants with impaired overall capacity, participants were rated as impaired if their score for any legal standard was less than 2.5SD below the comparison group mean, as impairment on any legal standard requires a clinical finding of incapacity."

${ }^{16}$ Grisso and Appelbaum 1998b: 128-141.

${ }^{17}$ Palmer and Salva 2007: 1047.

${ }^{18}$ Palmer and Salva 2007: 1053. Despite this essentially negative result, Palmer and Silva argue that there are "clear pragmatic implications" from this line of research. "Most notably," they argue, it shows that "across
} 
our purposes here is not the presence or absence of robust neurophysiological correlates of MacCAT-T performance. These may well emerge in future research. ${ }^{19}$ The critical point to notice is the way in which this neurophysiological research has intensified a trend already manifest in Grisso and Appelbaum's original approach: the mapping of decisional competence onto individual cognitive performance.

We turn now to the central challenge that concerns us: is there a way of harnessing the resources of phenomenology in tackling these problems concerning decision-making competence? If so, how might a phenomenological approach diverge from or supplement the well-established framework of the MacCAT-T? In pursuing these questions here we take up two complementary strategies. First, we believe that there are important results from the phenomenological 'canon' that can usefully be brought to bear on the challenge. To put the central lesson concisely: phenomenological research teaches us that the exercise of judgement always takes place in a world. We use the term 'world' broadly in the spirit of Heidegger. ${ }^{20}$ A world, in the sense we intend, is a context of intelligibility, a context in which things 'make sense' or are available for interpretation, in which normatively significant differences among different options present themselves. In navigating a decision situation the salient factors in my experience may be the various options available to me, the risks and benefits of each, etc. But all this figures in my experience only insofar as I am already situated - and more-or-less oriented - in a worldly context. ${ }^{21}$ Accordingly, the first element of our phenomenological approach shall be to focus on the worldly character of judgement and decision. Since world structure itself is notoriously difficult to bring into explicit focus, we propose to take up this lead by attending to three factors that play a significant role in structuring the world of judgement: time, others and identity.

The second component of our phenomenological strategy is what we shall call second-person phenomenology. In its classical form, phenomenology earned a reputation as a largely reflective, firstpersonal enterprise. If I want to learn about the structures of experience it may seem that I have no choice but consider the structures I discover in my own experience. Classical phenomenology laid the foundations for overcoming this myth, and at times actively resisted it. Nonetheless, the classical phenomenological discussions of 'the experience of others' have characteristically taken the form of an investigation of the experience of alterity - that is, those forms of experience where the intentional object of experience is another self or subject. ${ }^{22}$ In second-person phenomenology, by contrast, the concern is not so much with my experience of others as with the other person's experience itself. That is, the phenomenological inquirer sets out to understand and articulate what is distinctive about the

neuropsychiatric and other medical populations, clinicians and researchers should be alert to the presence of cognitive deficits when providing informed consent" (op. cit., 1055).

${ }^{19}$ One fMRI study focusing on consent forms has established that "good understanding of a consent form relies, at least in part, on adequate engagement of brain systems known to be involved in encoding verbal information" Eyler et al. 2007: 141 .

${ }^{20}$ See for instance Heidegger $1927 / 1962, \S 14$.

${ }^{21}$ A world in this sense is not simply a collection of objects, nor is some kind of flatly uniform space in which objects have locations and trajectories. It is a textured hermeneutic context in which we encounter, among other things, circumstances that call for decision.

${ }^{22}$ Husserl 1931/1950, Levinas 1961/1969. 
perspective and experience of another individual. This is a form of phenomenological undertaking that is less well-represented in the standard phenomenological canon, but it is an enterprise that occupies an important place in psychiatric practice and pastoral care more generally; it can and should be a fertile resource in phenomenological research.

In what follows we argue that the MacCAT-T is insufficiently informed by an understanding of the world of judgement as experienced and navigated by patients facing a treatment choice. While there is scope for second-person phenomenological probing in a MacCAT-T interview, we shall show that the test is, in its standard application, insufficiently phenomenological. To be clear, we shall not claim that a phenomenologically nuanced assessment of mental competence ought not avail itself of data provided by tools like the MacCAT-T. Individual cognitive performance criteria are, after all, an important component of mental competence, and the MacCAT-T provides a useful starting point for their assessment. But we argue that the MacCAT-T fails to highlight areas of mental capacity that a more phenomenological approach shows to be integral to the exercise of judgement, and that a strong performance in a MacCAT-T assessment is accordingly neither necessary nor sufficient for competence.

In broaching these matters, we begin by noting a certain configuration of experienced time that plays a central role in capacity assessments conducted with the MacCAT-T. Recall that one category of assessment under the MacCAT-T is reasoning. That is, the assessor attempts to probe the patient's ability to reason about the treatment decision she faces. In practice, this means that the patient is prompted to paraphrase what we shall call future subjunctive information. A patient might be asked, for instance, about the likely outcome if she were to go ahead with a recommended course of treatment, and about the possible consequences if she were to refuse. Such questions concern a future state under a particular assumption - hence 'future subjunctive. ${ }^{23}$ Future subjunctive questioning in an assessment of reasoning capacity exhibits a natural affinity with classical models of the structure of rational decision-making under conditions of uncertainty. Under such classical models, a rational subject operates with established preference rankings for possible future outcomes, and then makes a rational decision by rating the likelihood of various outcomes in light of a variety of present actions. A classically rational judge will maximize expected utility. To be sure, a patient involved in a MacCATT assessment will not be expected to perform Bayesian calculations. But in keeping with the classical model, the form of future subjunctive questioning is designed to probe the patient's capacity to compare various possible and variably desirable futures. Call this future subjunctive reasoning.

But how does time figure in the 'worldly' judgement of a patient faced with a treatment decision? There is certainly no simple answer to this question, but if we take a second-personal phenomenological perspective we soon encounter temporal complexities that go beyond the future subjunctive. Consider an example. As we have seen, a MacCAT-T assessor prompts a patient to speak of various possible futures; his right to refuse or consent to treatment may well turn on his ability to do

\footnotetext{
${ }^{23} \mathrm{We}$ do not mean to suggest that such questions necessarily make use of the subjunctive grammatical mood. Under the MacCAT-T protocol, a characteristic question in such an exchange might be framed as follows: "What do you believe will happen if you are not treated?" See Grisso and Appelbaum 1998a: 88.
} 
so. But when patients are asked in a more open-ended and less structured way about medical decisions, their replies often come in the past tense. One patient tells a story about something that happened to his father; another about an earlier episode in his own medical history. In some instances these past tense claims are supplemented by future subjunctive information, but it is not unusual for a patient's account of his decision to be entirely in this 'personal-historical' mode.

On a classical model of decision and judgement, such information is at best ancillary; it can play a role in rational deliberation only insofar as it serves to warrant or motivate some future subjunctive claim. But this fails to capture the significance of a patient's invocation of the past in navigating fraught decision situations. In the vocabulary we introduced above, the retention of critical episodes from the past plays an important role in world structure. A patient's decision is of course always in a fundamental sense about the future, but making a decision requires that one find orientation in the present. And this orientation often comes as much by the way we retain and appropriate a meaningful past as by the way we calculate over future possibilities.

With this we can begin to recognise the ways in which different 'temporal capacities' play a role in navigating treatment decisions. Once again we take our orientation from a second-person standpoint. Consider an encounter with a severely depressed patient, whether from the position of a clinician or social worker or family-member or friend. Discussions about the future in such encounters often take on a distinctive texture and tone. The depressed individual may exhibit reluctance to speak about the future; the pace of conversation slows; replies become truncated, dismissive or nihilistic. In discussions about treatment options the patient express a surety that nothing of the essentials of their condition could ever change. "It doesn't matter which option I choose; it won't make any difference." In seeking to understand and articulate the experience of such an individual, we must treat the probe of future subjunctive reasoning as a starting point for teasing out a more fundamental temporal phenomenology. Notice, first, that such a patient may be perfectly able to reason in the future subjunctive mode; indeed their despair may be expressed in precisely that modality. But what threatens to undermine decision-making capacity is here the distinctive form of ossification the patient finds in his future. For this patient, the future simply holds more of the same - not in the sense that nothing will happen, but in the sense that nothing significantly different will ever happen, nothing fundamentally better or worse. This form of temporal ossification can be debilitating, and it points us toward a different set of temporal capacities at work in the navigation of decision situations. Ultimately, what is most important about the patient's ability to paraphrase future subjunctive information is the underlying ability to project oneself into normatively different futures, and the ability to link that experience back to a sense of options available now.

When a patient navigates his treatment decision by recalling a story about his father we can begin to see a second important feature of the phenomenology of judgement: the role of others. As we have seen, the MacCAT-T assesses the capacity to judge by examining individual cognitive performance. Viewed in one light, this makes perfect sense. It is, after all, the mental capacity of an individual patient that is in question; it is the legal rights of an individual that hang in the balance. So 
obviously it is individual mental capacity that must be assessed. But what is obvious in one light can come to seem dangerously one-sided in another. Legally speaking, it is indeed one individual who ultimately makes a decision about treatment; the patient's signature at the bottom of a consent form is perhaps the best emblem of this juridical individualism. But the exercise of judgement is rarely a solitary undertaking. Deciding for oneself is not something that one typically does by oneself.

Our emblematic consent form provides a useful illustration of this point. The patient's signature may appear on its own at the bottom of that document, but the document itself was prepared by someone else, indeed typically by a host of others in consultation and cooperation. Moreover, most individual patients are hardly able to understand all the technical medical information contained in the form. They rely on clinical staff to select and explain the important information and may depend on friends and family to help them think it through. Even the doctor may not fully understand all the information on her own; any moderately complex body of scientific knowledge is characteristically spread over a community of practitioners, with no one practitioner fully in possession of the totality. This is, among other things, a corollary of what has been called 'the division of linguistic labour. ${ }^{\text {24 }} \mathrm{A}$ phenomenologically realistic account of judgement must somehow come to terms with the fact that most decisions are undertaken in what we shall refer to as decision communities.

Here we find it useful to introduce a distinction among different forms of plurality in decision communities. We are happy to allow that there may be some decisions that are wholly first-person singular. Perhaps Robinson Crusoe decided all by himself to reserve the whole of his first harvest of grain rather than eating any of it. But in most interesting and important cases, decisions take place in some kind of community with others. The forms of community vary in important respects. In some cases, the agent of judgement (the ' who' of judgement) is itself a corporate entity. Our family decides together where to go on holiday; the electorate as a collectivity elects its leader. We shall call these 'first-person plural' decisions: we decided where to go, and no one of us can truly say 'I was the one who decided. ${ }^{25}$ First person plural decisions have been much studied, traditionally in political science and more recently in action-theory. ${ }^{26}$ But the cases that are most important for our purposes are cases of first-person singular judgement that are nonetheless not solitary judgement. These are the cases where someone can aptly say 'I decided,' and experience themselves as the author of their decision, yet it is nonetheless the case that others played an essential role not only in facilitating the particular exercise of judgement, but in constituting the capacity for autonomous judgement itself.

Consider how this plays out from the second-person perspective. An Alzheimers patient suffers cognitive deficiencies that increasingly compromise his ability to communicate: in speech he finds himself unable to complete his sentences because of an intermittent but chronic inability to recall even mundane vocabulary; in writing he cannot recollect spellings. When we assess his individual cognitive performance, significant deficits come to light. But when we encounter him in his decision

\footnotetext{
${ }^{24}$ Cf. Putnam 1975: 144

${ }^{25}$ In some interesting cases of first person-plural judgement it is not even the case that any one member of the decision community favoured the decision that was taken. The electorate as a corporate entity elected the current Parliament; but perhaps no one voter actually wanted it.

${ }^{26}$ For a recent discussion, see Westlund 2009.
} 
community, this individual can nonetheless carry on substantive communicative exchanges. This is because he finds himself embedded in a community of family members and carers who have an intimate understanding of his situation, his preferences, his concerns, and so on. These others do not make decisions on his behalf, but they are able to help him complete his sentences. Although the patient himself does not always recall the words he wants, he clearly recognises and indicates when others express his thoughts correctly, and he decisively stops them when they get it wrong. Faced with a treatment decision, this patient relies on his community of intimates. Notice that this is not a case of 'best-interests' or surrogate decision-making. The patient makes his own decisions, and experiences himself as the author of his decisions, often overriding the better judgement and protests of others. Neither is this a case of first-person plural decision, in the sense specified above, where the members of a decision community collectively reach a decision. What we have here is rather an instance of what we shall call distributed capacity. It is in virtue of a communicative partnership that the patient is able to discuss and assess his treatment options with clinical staff, understand and weigh the options, and communicate his own decision. So his capacity to decide for himself is itself distributed in that community of others.

There are, of course, many different forms that these partnerships can take. Not all 'partners' are good ones, and not all decision communities are functional. We return to this point below. But notice already a critical corollary of the more general point: the capacity of such a patient to exercise judgement in making decisions for himself may be substantially altered simply by a change in his decision community. If his capacity is distributed and his partners become impaired or their relationship disrupted, this can itself serve to deprive him of his capacity. This fact will be missed by any metric of capacity that confines its attention to individual cognitive performance: where capacity is distributed, individual cognitive performance can remain constant while the capacity for autonomous judgement varies substantially. ${ }^{27}$

A third pertinent feature of the phenomenology of judgement is what we shall call 'identity. ${ }^{28}$ Start with a familiar pattern of exchange in a second-person encounter. When pressed to explain how he has reached some decision or another, our interlocutor responds with a certain sort of first-personal claim about himself: 'I am a father;' 'I am a curious person;' 'I am a teacher (or nurse, or firstresponder ...).' In the limiting case he might simply say, 'That's just the kind of person I am.' In one way such a remark might seem to be vacuous - more a refusal of explanation than the provision of one. But phenomenologically such facts are anything but empty; this move in the game of asking for and providing reasons often expresses an important clue about the structure of the world in which decision situations are encountered and judgements made.

In thinking about just what identity is, we find it useful to begin from Hewitt's influential characterization of the phenomenon. Hewitt characterizes identity as "a sense of self built up over time as the person embarks on and pursues projects or goals that are not thought of as those of a community,

\footnotetext{
${ }^{27}$ On the role of families in making medical decisions, see Ho 2008 and Slowther 2006.

${ }^{28}$ The notion of identity with which we are concerned is not to be confused with the notion of numerical sameness that has played a role in the long-standing metaphysical debates about personal identity over time.
} 
but as the property of the person." 29 Hewitt's formulation concisely captures several important aspects of the phenomenon. The implicit notion of ownership in Hewitt's definition ("property of the person") proves to be particularly important phenomenologically. To be possessed of an identity is not simply to exhibit certain classifiable character traits, but to experience certain patterns of motivation as distinctively 'one's own.' Psychiatric diagnostics recognise this phenomenon in deploying the distinction between ego syntonic and ego dystonic states; in Heideggerian phenomenology it has been investigated under the heading of authenticity (Eigentlichkeit, self-owning). The crucial point for our purposes is the way in which the possession of an identity predelineates our experience in circumstances in which judgement is exercised in making decisions, providing a sense of orientation already in place prior to undertaking particular deliberations. Arriving at an accident scene, a veteran first-responder does not consider whether to offer assistance to a stranger in distress. For her to have that identity is to inhabit a world where that question is already settled; the questions for deliberation in the moment of action are technical and instrumental questions about the best and most appropriate methods for carrying out the task at hand.

These three features of the phenomenology of judgement - time, others, identity - are not unrelated. Indeed we believe that they are intricately interconnected. To have an identity is itself a temporally articulated phenomenon. As Hewitt's definition indicates, an identity is something that is built up over time, and that manifests itself in time and over time. It involves the capacity to appropriate the events of one's past, to find a unity in them, and to project oneself accordingly into the future. And this itself is something that plays out in our ways of being with others in variously complex relationships, most explicitly when we look to others as role models or exemplars by reference to whom we come to understand what it is to have a certain kind of identity. All this suggests that there are some quite fundamental capacities - the capacity to participate in decision communities, the capacity to find orientation in a hermeneutically complex present moment, the capacity to have and sustain an identity - that are elements of the complex capacity to judge. In each case, these are elements of the phenomenology of decision-making that manifest themselves in secondperson encounters and play a role in structuring the world in which particular decisions are encountered and resolved. A phenomenologically informed capacity assessment must accordingly be attuned to these components of decisional competence.

We turn now to consider how attention to these dimensions of capacity bear on the assessment of two particular cases of disputed capacity to judge. We begin with a case that has recently been adjudicated in the English Court of Protection. ${ }^{30}$ Mrs. A suffers from a significant learning disability; court papers document that her IQ is in the bottom one percentile of adults of her age. Her background story is excruciating. Prior to meeting her husband, she had twice become pregnant. Although she insisted that she would be a good mother, a pre-birth assessment in each instance concluded that she lacked the insight to meet her baby's needs without intensive support. Under court order, her two

\footnotetext{
${ }^{29}$ Hewitt 1997: 93.

${ }^{30}$ A Local Authority v Mrs. A and Mr. A (2010); High Court of Justice, Family Division (Mr. Justice D. Bodey); Case Number 11753201.
} 
infants were removed at birth. After the second pregnancy, Mrs. A herself came under a Guardianship order and began using contraception, administered by a monthly injection.

Mrs. A met Mr. A. in 2007; they were married in 2008. Mr. A also falls in the bottom one percentile in IQ. It soon became clear that the question of children was a vexed one in the relationship. Court documents record that Mrs. A told a number of acquaintances that she did not want children; it is evident that Mr. A did. Their relationship seems also to have become abusive, with Mrs. A regularly reporting that her husband had hit or punched her, or would shout and break household items. At times she was afraid to go home. She showed up at her college showing bruises on her arms.

Mr. A became increasingly insistent that Mrs. A should not continue her contraceptive injections, and moreover should not be in touch with representatives of Social Services. At times he actively prevented her from contact. When Social Services did come to their place of residence, Mr. A prevented them from speaking to Mrs. A alone. In Mr. A's presence Mrs. A indicated that she no longer wished to use contraception. She signed a letter, written by Mr. A, indicating that she no longer wished to be contacted by Social Services. She stopped going to college, where she was enrolled in an Adult Education programme, apparently because Mr. A objected to the fact that her course-coordinator facilitated contact with Social Services, whom he viewed as "interfering in our sex life" and prying into private family affairs. In September, 2009, the Court of Protection became involved. The Local Authority asked the court to declare that Mrs. A lacked the mental capacity to decide, among other things, whether she should be administered with contraceptive devices. ${ }^{31}$

Under English law, as we have seen, an adult has a right to refuse medical treatment for any reason, provided that they have the mental capacity to make the relevant decisions. The law operates with a strict presumption of capacity; paternalistic intervention is permissible in these circumstances only on the basis of a finding of incapacity. ${ }^{32}$ So how should a court or a consulting psychiatrist approach its assessment of Mrs. A?

Court records show no evidence that Mrs. A was subjected to a MacCAT-T assessment, but from the judge's decision it is not hard to piece together the main elements of her rating against that standard. Paragraph 44 of the Judge's ruling reports on Mrs. A's meeting with two Gynaecological specialists:

Miss $\mathrm{O}$ and Mr I, both Consultant Gynaecologists and Obstetricians, jointly examined Mrs. A on $21^{\text {st }}$ December, 2009. Mrs A told them that she had had the contraceptive injection in the past, but did not like the side-effects. She was aware of the coil and how and where it is fitted. She said that she and Mr. A would like to have a child in the next year or two. She denied any coercion by him, but 'admitted he might leave her if she does not have another child.' They considered that she answered their questions appropriately and concluded that: 'she understands her contraceptive choices ... [although] ... she did not want to make any decision today without consulting Mr. A first and involving him in the decision-making process.

Paragraph 45 summarises Miss O's expert testimony in court, reporting Miss O's opinion that:

\footnotetext{
${ }^{31}$ The Local Authority also sought a ruling that Mrs. A lacked sufficient mental capacity to decide where to live, and what contact to have with Mr. A. For present purposes we confine our attention to the issue pertaining to the treatment decision.

${ }^{32}$ Mental Capacity Act (2005), §1.2.
} 
Mrs A had understood all the elements which [Miss O] regards as necessary for capacity as regards contraception: namely as to prognosis, diagnosis and an understanding of the medical treatment involved, the common methods, how they are used and the possible side-effects..$^{33}$

In sum, the record shows clear evidence that Mrs. A understood the treatment decision facing her and was able to paraphrase the treatment options that had been explained to her; she was able to engage in what we have called 'future subjunctive reasoning,' and she had demonstrated her capacity to express a choice about treatment.

But from what we have seen, a MacCAT-T assessment conducted on this basis would risk missing some of the most important aspects of Mrs. A's capacity. If we focus narrowly on individual cognitive performance criteria, then we fail to attend to those aspects of Mrs A's circumstance that are the greatest threat to her capacity. These are not in fact her low IQ, but the form of decision community in which her decision is embedded. In short, it is only when we consider the role of Mr. A that we can begin to gauge Mrs A's capacity. Here it is significant that Mr. A not only exerted direct pressure on Mrs. A to discontinue contraceptive treatment, apparently including both direct physical abuse and threats to leave her; he also actively prevented Mrs. A from contact with others with whom she might have sought to think through her decision. He prevented her from having private consultations with representatives of social services and answered on her behalf in jointly conducted interviews; he pressured her to discontinue her studies at the local college, and thereby disrupted the contact with Student Support Services that she had made use of there. In short, Mrs. A found herself in a dysfunctional decision community; that dysfunctionality directly threatened her ability to make a decision for herself, despite her performance when measured against the MacCAT-T standard.

We do not mean to suggest that this makes a ruling in the case of Mrs. A straightforward.

Nothing could be further from the case. Our point is rather that any serious assessment of her capacity must take seriously elements that go beyond individual cognitive performance criteria. This was, in the end, the view of the court as well.

In view of what I find to be the completely unequal dynamic in the relationship between Mr. and Mrs. A, I am satisfied that her decision not to continue taking contraception is not the product of her own free will. In this respect I do accept the opinion of Dr K and fully agree with him that she is unable to weigh up the pros and cons of contraception because of the coercive pressure under which she has been placed both intentionally and unconsciously by $\mathrm{Mr}$ A.... For these reasons, I am in no doubt that Mrs A presently lacks capacity to take a decision for herself about contraception. (para. 73)

We do not wish here to take a position on the correctness or incorrectness of the judge's finding. ${ }^{34}$ Nonetheless we believe that he was correct to see that it was, in our terminology, the structure of Mrs

\footnotetext{
${ }^{33}$ One of the subsidiary issues in the Mrs A case concerns the proper standard of reasoning in treatment decisions involving contraception. The relevant statute supports a finding of incapacity for an individual who is unable to understand the foreseeable consequences of a refusal of treatment. But just what does this require when a sexually active woman refuses contraceptive treatment? The Local Authority held that "understanding the foreseeable consequences" in this case required that Mrs A be able to "understand and envisage ... what would actually be involved in caring for and committing to a child" (para. 56). But the judge sided with the Official Solicitor, who argued that such a standard would "deny capacity to large numbers of women, including many first-time mothers, who would presently be viewed as having capacity regarding contraception" (para. 57).

${ }^{34}$ It is important to note that while the judge found Mrs A to be lacking in mental capacity to make the decision about contraception, he nonetheless did not support the Local Authority in their petition to administer
} 
A's decision community that proved the critical factor, and that a narrow assessment of Mrs A's individual cognitive performance was not sufficient to settle the disputed question. ${ }^{35}$

We turn finally to consider how a phenomenologically informed capacity assessment might be conducted in the particularly difficult context of paranoid schizophrenia. John was in an English prison awaiting trial on a criminal charge. ${ }^{36} \mathrm{He}$ had a history of schizophrenia. While in prison he refused to accept medical treatment for his mental disorder, and his symptoms worsened. When he began to exhibit psychotic delusions, he was transferred to a secure psychiatric unit of the NHS, where he was detained under the provisions of the Mental Health Act, which provides that a mental disorder can be treated involuntarily in a patient's own interests and in the interests of public safety. ${ }^{37}$ Every two weeks John received an injection of anti-psychotic medication. Under his medication regimen, his psychotic symptoms were by-and-large under control, although they tended to recur at the end of each medication cycle.

But John also had other problems. While in prison, he had developed a chronically hoarse voice and laboured breathing. After being transferred to hospital his throat was examined and he was diagnosed with advanced laryngeal cancer -- cancer of the voice box. The indicated treatment was surgical removal of the larynx, together with the fitting of a valve in the throat that would allow him to breathe and generate sound. John met with the surgeon, who explained the condition and the urgency of the procedure. The cancer was spreading and restricting his airways; without surgical intervention the condition could well be fatal in a matter of weeks. John appeared to understand what he was told, and agreed to go ahead with the surgery; back at the psychiatric unit he told his psychiatrist and his advocate about the plans for the surgery. But a day or two later he changed his mind. He began to say that the proposed operation was a conspiracy to stop him from smoking. He was convinced that ENT doesn't stand for 'Ear, Nose and Throat', but 'electroneurotherapy,' a fictional treatment that would put him under anaesthetic and kill him.

There is quite a lot more to say about John's case, but already with this much of his story we can see the basic structure of a characteristic dilemma of care. John has a life-threatening physical ailment, one that requires urgent and dramatic medical intervention. But he does not give his consent or rather, he does not give his continuing consent - to the medical procedures that are required. His doctors and psychiatric team face an excruciating choice: they can honour John's refusal of care and let him die, or they can sedate him and remove his voice box without his consent. Legally, everything

contraception against her will, arguing that, on balance, this would not be a course of action in Mrs A's best interests.

${ }^{35}$ According to Grisso and Appelbaum, the stated aim of a competence assessment must ultimately be "to reach the same judgement as would result from judicial proceedings[,] ... to mimic the judgement that would be reached by a court in that case" (Grisso and Appelbaum 1998a, 129). The Court of Protection ruling in the case of Mrs. A makes it clear that success by this measure must, as we have argued, go beyond the measurement of individual cognitive performance.

${ }^{36}$ Our description of John's case is drawn from a radio documentary (BBC Radio 2010); all quotes pertaining to John are taken from the published transcript. We are grateful to Beth Eastwood of the BBC for sharing materials used in the preparation of this broadcast.

${ }^{37}$ Mental Health Act (1983, rev. 2007), §3.2. 
turns on an assessment of his mental capacity - his ability to exercise his own judgement in making a decision for himself about whether to submit to a life-changing medical intervention. ${ }^{38}$

Time is clearly a factor in John's decision-situation, and this in a number of respects. Medically, there is considerable pressure to reach a definite decision about whether to proceed with surgery, given John's steadily deteriorating condition. Moreover, going ahead with a complex surgery itself requires some advance planning: booking a surgical theatre and team, making the necessary arrangements for security, and so on. Delay thus incurs financial costs as well as medical risks. But John's own inconsistency over time is very much an issue here as well, and that inconsistency may in turn have to do with the temporal rhythms of the medication regimen for the treatment of his psychosis.

If we approach John's case with a focus on individual cognitive performance criteria, then much will depend upon when the assessment is administered. In his delusional state it seems clear that John would not score well in the 'understanding' portion of a MacCAT-T interview, and would fail to exhibit 'appreciation' for how the information provided by the doctors applies to his situation. These deficiencies in turn undermine his ability to 'reason' about the risks and benefits of the treatment. If he fails to appreciate the possible risks and benefits of the proposed treatment, he can hardly 'weigh them in the balance.' But does this mean that John should be found incapacitous? This conclusion also seems problematic. In the interview with the surgeon and subsequent discussion with his psychiatric team, John showed good understanding of his situation, and indeed the surgeon took the view that he had sufficient capacity to undertake valid consent to the treatment. So when John's case is approached within the confines of the MacCAT-T we reach an impasse. We seem to face an arbitrary choice between two times of assessment, with the different times yielding diametrically opposed results.

Would a phenomenologically informed assessment fare any differently? The phenomenological tradition has of course long resisted any model that reduces human experience to a series of time slices. ${ }^{39}$ Rather than thinking of John's situation in terms of 'capacity-at-a-time,' we need a perspective on John's circumstances that can treat both times-of-assessment as abstractions from a single picture of John's unfolding experience of an intrinsically stressful situation. We think of this as an application of the phenomenological principle of adumbration. That principle is canonically illustrated with the experience of a physical object: what we are presented with in any one encounter is but one façade of the thing, but also thereby an 'adumbration' of further possible experiences of the same entity. ${ }^{40}$ We must remember that a capacity-assessment interview presents us with one 'façade.' The task is not to assess that façade; it is to assess John, who is never fully presented to the assessor in a single experience or encounter. This already changes our framing of the dilemma: the task is not to choose between two pictures of John's capacity, but rather to integrate them into a single portrait of the

\footnotetext{
${ }^{38}$ An MHA section provides for involuntary treatment of John's mental disorder, but it does not provide the basis for involuntary the treatment of an unrelated physical disorder.

${ }^{39}$ See for instance, Heidegger 1982, $§ 18-19$, and Heidegger 1962, § 81.

40 "I see a thing, e.g. this box, but I do not see my sensations. I always see one and the same box, however it may be turned and tilted. I have always the same 'content of consciousness' -- if I care to call the perceived object a content of consciousness. But each turn yields a new 'content of consciousness', in a much more appropriate use of words. Very different contents are therefore experienced, though the same object is perceived." Husserl 1900/1970, 565.
} 
whole. To be sure, this reframing does not make the problem go away, but it does serve to resituate the challenge.

Here the role of others and identity becomes critical as well. To see this it will help to know something of the rest of John's story. As it transpired, the dilemma over John's capacity led to a series of interventions. The surgical team, with advice from lawyers at the hospital, composed a letter to John, in which they laid out, in quite stark terms, the medical situation as they saw it. John's family was involved in reviewing the letter with John, and together they talked about the shape of John's life, what he had to look forward to, etc. The psychiatric team once again adjusted his medication. In short, John found himself in the centre of a quite complex decision community, and his decision was ultimately taken from that position. John ultimately did consent to the surgery. In a subsequent interview, speaking now through his newly fitted valve, he summed up the whole episode in these terms: "The psychiatrist did say to me [that] someone else would have to make the decision because I was changing my mind. But I made the decision on my own in the end."

Seen in one way, we might well conclude that John is here mistaken. How can we say that he made the decision on his own when it is plain that so many other people played a critical role in supporting, enabling, and shaping that decision? But it would be our error simply to dismiss John's report as a mistake. As we have argued, in circumstances of distributed capacity, others can play a constitutive role in a person's ability to make a decision for himself. In this case, it is striking that John retrospectively experienced his decision as his own, and reported it using the first person singular pronoun. Obviously this is not a consideration that could have entered directly into the psychiatric assessment in advance of the surgery, but we should not therefore discount it as an element of John's capacity. In any adequately complex understanding of the distinctive temporality of deliberation, this ability to retrospectively 'own' a decision must be seen as part of the capacity for independent judgement. And this in turn is inextricably tied up with the possession of an identity over time. Recall Hewett's definition: to be possessed of an identity is to have a sense of self such that some project can be "thought of ... as the property of the person." If we treat the possession of an identity as an element of capacity, and the ability to 'own' one's decisions as a component of identity, then John's post facto report can be seen as one indication of his capacity. We thus find considerable significance in the fact that this was an element of the situation to which members of John's decision community were specifically attentive. As one member of his psychiatric team subsequently reported:

My biggest anxiety is that he might wake up the day after the operation without a voice box and then he would say, 'I've never consented to this, this was all part of the conspiracy.' That was my biggest anxiety.

What the psychiatrist reports here as an anxiety must also be seen as a sensitivity to an important dimension of the situation. In other words, John found himself in a decision community that was determined to find ways of helping John navigate the circumstance of judgement so as to facilitate his subsequent, retrospective ownership. ${ }^{41}$

\footnotetext{
${ }^{41}$ It may of course be the case that the anxiety expressed by John's psychiatrist was in part (perhaps in large part) a matter of self-interested concern. If John had emerged from surgery denying that he had given his consent, this would certainly not have been seen as an optimal clinical outcome, and could well have led to a range of
} 
This small detail helps to illustrate one point we have been pressing here, that others can play a substantial role in shaping the outcome of a deliberation, without thereby compromising the autonomy of the ensuing decision. The point is in one way obvious: among other things, our decisions are everywhere informed by evidence and advice provided by others. But it points to what should, in our view, be an important dimension of a phenomenologically informed capacity assessment. We should recognize that our capacity to make decisions for ourselves is constituted in part by our ability to participate in relationships with others in our decision community, and by the structure of that decision community itself.

We do not mean to deny that decision communities can also serve to undermine capacity, whether by exerting undue pressure and influence, undermining confidence, distorting the process of balancing risks and benefits, etc. That, indeed, was the main conclusion we sought to draw from our discussion of the case of Mrs A. We shall not here hazard any general standard whereby one might distinguish functional from dysfunctional decision communities; we believe that this is an area that merits a great deal of further scrutiny. But the case of John helps to highlight one important role that a functional decision community can play in circumstances of schizophrenia. For John, the most important capacity-inhibiting factor lay in his tenuous understanding of the realities of his decision situation. Because of his psychiatric disorder, his deliberation often failed to be guided and shaped by the facts of his situation. In the suggestive phrase of John McDowell, there was a failure of 'friction' between John's mind and John' world. ${ }^{42}$ It is one of the great merits of a MacCAT-T assessment that it brings this deficiency sharply into view. The crucial point, however, is that John's decision community played a role that served to compensate for this deficiency. Through a variety of interventions, his decision community sought to ensure that John's deliberation was engaged with and responsive to the realities of his situation - whatever his final conclusion. In so doing, those others facilitated John's capacity, supporting his ability to make a decision for himself.

Our conclusions from the foregoing discussion must of necessity be tentative and provisional. We wish to reiterate, first of all, that we by no means wish to dismiss the MacCAT-T altogether. There are enormous advantages in having a short, easily administered, broadly validated tool to structure the investigation of contested capacity. Moreover, the 'semi-structured' character of the MacCAT-T interview leaves scope for the assessor to probe some of the dimensions of capacity that we have emphasized here. Indeed one way of applying the lessons from our phenomenological investigations would be to incorporate them into the administration of MacCAT-T assessments. Grisso and Appelbaum themselves have little to say about the ways in which the world-structuring factors of time, others and identity figure in capacity assessments. But there is nothing in principle to preclude incorporation of such factors into 'good practice' guidelines for use of the MacCAT-T.

administrative investigations or legal challenges regarding the taking of John's consent. But this dimension of the psychiatrist's motives does not change the crucial fact. For whatever reason - altruistic or self-interested or some combination of the two - members of John's team were determined to navigate the dilemma in such a way as to foster John's 'ownership' of the outcome.

42 McDowell 1994. 
Our most important result concerns the intrinsic dangers in any capacity-assessment technique that confines its attention to individual cognitive performance criteria. In particular, we have established that strong performance measured against individual cognitive criteria is neither necessary (the Alzheimers patient) nor sufficient (Mrs. A) for the capacity to make decisions for oneself. At a minimum we would argue that a phenomenologically informed capacity-assessment must take into consideration the capacity to participate in decision communities, acknowledge the fact that capacity can be distributed in such communities, and consider the ways in which a patient's particular decision community serves to foster or undermine capacity. Any capacity-research that focuses attention 'between the ears' will of necessity remain blind to such factors. We also believe that there is a need to develop techniques for the assessment of what we have called temporal capacities. The capacities in question should not be confined to the ability to engage in future subjunctive reasoning, but must also probe the experienced temporality that underlies such reasoning: the ability to knit together one's past experiences in such a way as to project oneself meaningfully into an uncertain and existentially open future. For it is in so doing we exercise the kind of 'ownership' of our decisions that is partly constitutive of identity and the capacity for autonomous choice.

Husserl famously insisted that phenomenology must return "to the things themselves." In the present context, this requires that any clinical or legal assessment of mental capacity should be firmly rooted in an understanding of the exercise of judgement as a human experience. We must not begin from an account of what we think decision should be and then devise clinical instruments to assess patients against that standard. We must instead begin from a better understanding of the ways in which individuals - whether or not they are suffering from a mental disorder - navigate the decisionsituations that they encounter. ${ }^{43}$

\section{REFERENCES}

Appelbaum, P (2007). “Assessment of Patients' Competence to Consent to Treatment," The New England Journal of Medicine 357:18, 1834-1840.

BBC Radio (2010). "Mentally Ill and Refusing Surgery” Inside the Ethics Committee, Series 6, Episode 1 (London: BBC/OU Co-Productions); originally Broadcast 20 July, 2010. Transcript and recording downloaded from http://www.bbc.co.uk/programmes/b00t1xsz; accessed 1 August, 2010.

Breden, T. and Vollmann, J. (2004). "The Cognitive Based Approach of Capacity Assessment in Psychiatry: A Philosophical Critique of the MacCAT-T," Health Care Analysis 12: 273-283.

\footnotetext{
${ }^{43}$ Support for the research presented here was provided by the UK Arts and Humanities Research Council. For invaluable feedback and research assistance, we wish to thank members of the research team of the Essex Autonomy Project (particularly Viv Ashley, Fabian Freyenhagen and Tom O'Shea), as well as Gareth Owen, Beatrice Han-Pile, Debra Harris, Dan Zahavi and Allison Glasscock.
} 
Cairns, R., Maddock C., Buchanan, A. (2005). "Reliability of Mental Capacity Assessments in Psychiatric In-Patients,” British Journal of Psychiatry 187: 372-8.

Cerbone, D. (2003). "Phenomenology: Straight and Hetero" in C.G. Prado (ed.) A House Divided: Comparing Analytic and Continental Philosophy (Amherst, N.Y.: Humanity Books), 105-138. Dennett, D. (1991). Consciousness Explained (Boston: Little, Brown and Co.).

Dunn, L., Nowrangi, M., Palmer, B., Jeste, D. and Saks, E. (2006). “Assessing Decisional Capacity for Clinical Research or Treatments: A Review of Instruments," American Journal of Psychiatry 163: 1323-34.

Eyler, L et al. (2007). "Brain Response Correlates of Decisional Capacity in Schizophrenia: A Preliminary fMRI Study," Journal of Neuropsychiatry and Clinical Neuroscience 19:2, 137144.

Frege, G. (1918/1997). 'Thought,' translation in M. Beaney (ed.), The Frege Reader (Oxford: Blackwell Publishing).

Grisso, T. and Applebaum, P. (1996). "Values and Limits of the MacArthur Treatment Competence Study," Psychology, Public Policy and Law 2:1, 167-181.

Grisso, T. and Applebaum, P. (1998a). Assessing Competence to Consent to Treatment: A Guide for Physicians and Other Health Professionals (Oxford: Oxford University Press).

Grisso, T. and Applebaum, P. (1998b). MacArthur Competence Assessment Tool for Treatment (MacCAT-T) (Sarasota, Florida: Professional Resource Press).

Grisso, T., Appelbaum, P., and Hill-Fotouhi, C. (1997). "The MacCAT-T: A Clinical Tool to Assess Patients' Capacities to Make Treatment Decisions," Psychiatric Services 48: 1415-1419.

Heidegger, M. (1927/1962). Being and Time, translation by J. Macquarrie and E. Robinson (New York: Harper \& Row).

Heidegger, M. (1927/1982). The Basic Problems of Phenomenology, translation by A. Hofstadter (Bloomington: Indiana University Press).

Hewitt, J. (1997). Self and Society: A Symbolic Interactionist Social Psychology, 7th edition (Boston: Allyn and Bacon).

Hickerson, R. (2007). The History of Intentionality: Theories of Consciousness from Brentano to Husserl (New York \& London: Continuum).

Husserl, E. (1900/1970). Logical Investigations, translation by J.N. Findlay (London: Routledge \& Kegan Paul). 
Husserl, E. (1913/1931). Ideas: General Introduction to Pure Phenomenology, translation by BoyceGibson (London: George Allen and Unwin).

Husserl, E. (1931/1950). Cartesian Meditations: An Introduction to Phenomenology, translation by Cairns, (The Hague: Martinus Nijhoff).

Ho, A. (2008). "Relational autonomy or undue pressure? Family's role in medical decision-making." Scandinavian Journal of Caring Sciences, 22:1, 128-135.

Levinas, E. (1961/1969). Totality and Infinity: An Essay on Exteriority, translation by Lingis, (Pittsburgh, PA: Duquesne University Press).

Marson, D. (2001). “Loss of Competency in Alzheimer's Disease: Conceptual and Psychometric Approaches," International Journal of Law and Psychiatry 24: 267-283.

Martin, W. (1999). "Husserl's Relapse? (Concerning a Fregean Challenge to Phenomenology)”; Inquiry 42:3-4, 343- 370 .

Martin, W. (2005). "Husserl and the Logic of Consciousness"; in D.W. Smith and A. Thomasson (eds.) Phenomenology and Philosophy of Mind (Oxford: Oxford University Press), 203-221.

Moye, J., Karel, M.J., Gurrera, R.J. and Azar, A.R. (2006). "Neuropsychological Predictors of Decision-Making Capacity over 9 Months in Mild-to-Moderate Dementia," Journal of General Internal Medicine 21: 78-83.

McDowell, J (1994). Mind and World (Cambridge, MA: Harvard University Press).

Merleau-Ponty, M. (1945/1962). Phenomenology of Perception, translation by Smith (London: Routledge).

Palmer B. and Salva, G. (2007). "The Association of Specific Neuropsychological Deficits with Capacity to Consent to Research or Treatment," Journal of the International Neuropsychological Society 13: 1047-1059.

Petitot, Jean et al. (eds.) (1999). Naturalizing Phenomenology: Issues in Contemporary Phenomenology and Cognitive Science (Stanford, Calif. : Stanford University Press).

Putnam, H. (1975). “The Meaning of 'Meaning," Minnesota Studies in the Philosophy of Science 7:131-193.

Slowther, Anne-Marie (2006). “The role of the family in patient care,” Clinical Ethics 1:4, 191-193.

Westlund (2009). “Deciding Together,” Philosopher's Imprint 9:10, 1-17. 